\title{
Digital Practice Spaces and Clinical Practice in Teacher Preparation: Current Uses and Future Possibilities
}

\begin{abstract}
(120 words)
This paper explores how the use of digital practice spaces (DPSs) can inform teacher preparation through a reimagining of clinical practice in teacher preparation by addressing the question: what roles might DPSs play in the ecology of apprenticeship opportunities for future educators? We leveraged AACTE's Essential Proclamations and Tenets for Highly Effective Clinical Educator Preparation as an analytical framework to examine our own experiences using DPSs in our teacher education coursework. We discuss the alignment between these proclamations and the theoretical, conceptual, and practical underpinnings of DPSs. Finally, we consider the remaining proclamations that represent the horizons of DPSs within teacher preparation, a task we undertook as a set of informed provocations, envisioning how DPSs could be designed to support the proclamations not currently supported.
\end{abstract}

Funding provided by the Hewlett Foundation 


\section{Digital Practice Spaces and Clinical Practice in Teacher Preparation: \\ Current Uses and Future Possibilities}

Talented, well-prepared classroom teachers are invaluable to the democratic experiment. Good teachers engage young people in the pressing problems of the day, help them develop the skills and competencies necessary to flourish within and give back to their communities, and prepare them to don the mantle of citizenship by engaging them in discussions of controversial issues. Thus, the preparation of classroom teachers represents one of the preeminent responsibilities of society at large and academic institutions in particular. In this spirit, the American Association of Colleges for Teacher Education's (AACTE, 2018a) published A Pivot Toward Clinical Practice, its Lexicon, and the Renewal of Educator Preparation, a report intended to offer guidance on teacher preparation.

An essential component of preservice teachers' preparation is practicing for future scenarios they might encounter in the field. In their coursework, teacher educators often ask preservice teachers to read textbooks and reflect on their past experiences as PK-12 students. Teacher educators present preservice teachers with problems of practice, and conversations ensue. However, this focus on a priori knowledge, or knowledge gained independently of experience, can be of limited worth to preservice teachers who lack teaching experience and cannot contextualize this knowledge within the experience of actual teaching (Clark \& Lampert, 1986; Darling-Hammond, 2014; John, 2007). As such, teacher educators need to expose preservice teachers to more hands-on experience with the situations they might encounter in their own classrooms. Much like a coach might start with a diagram on a white board, players still 
need to be able to 'walk through the game.' In the same way, teacher educators need to use similar walkthroughs, such as role-playing scenarios and emerging virtual practice spaces.

Exposing preservice teachers to these opportunities most often takes place in clinical practice experiences. AACTE (2018a) defines clinical practice as opportunities for preservice teachers to "work in authentic educational settings and [engage] in the pedagogical work of the profession of teaching, closely integrated with educator preparation course work and supported by a formal school-university partnership....traditionally known as field work" (p. 11). Many teacher preparation programs currently use a 'clinically accompanied' model of clinical preparation, where clinical placements occur simultaneously with coursework, but with little to no explicit connection between preservice teachers' coursework and fieldwork (Dennis et al., 2017; Yendol-Hoppey \& Hoppey, 2018). Although opportunities to apply skills learned in coursework can be useful, a wide chasm exists between knowledge and theories gleaned from class readings and discussions, on the one hand, and enacting this knowledge in a classroom with twenty-five real life students, on the other. Moreover, preservice teachers are often better equipped to make connections between theory and practice when they have teaching experience (Darling-Hammond, 2014). Thus, scholars have advocated strongly over the last decade to explicitly integrate approximations of clinical practice within teacher coursework (Ball \& Forzani, 2009; Dennis et al., 2017; Kavanagh \& Danielson, 2020; Lampert et al., 2013). Approximations of practice provide opportunities for preservice teachers to rehearse and receive feedback on teaching in low-stakes environments (DeGraff et al., 2015; Grossman et al., 2009).

In this paper, we focus on one particular space for approximations of clinical practice: digital practice spaces. Digital practice spaces are fully digital approximations of realistic professional scenarios that enable pre- and in-service teachers to engage in interactive cycles of 
practice, reflection, and feedback in low-stakes environments (Reich et al., 2018). Similar to platforms such as Mursion and TeachMe, digital practice spaces can be used within teacher preparation programs to approximate clinical experience within low-stakes environments (Bautista \& Boone, 2015; Howell \& Mikesa, 2021). Unlike some platforms, however, digital practice spaces do not require the use of actors to play the role of digital avatar with whom the preservice teacher interacts. Rather, digital practice spaces integrate text, audio, and video prompts within a simple web application. These interactive narratives allow instructional designers to simulate a variety of common scenarios that often present significant challenges to preservice teachers without requiring actors or specialized equipment. The limitation of this approach is that digital practice spaces may not feel as responsive or authentic as interactions with an actor. Yet, the simple, low fidelity design allows digital practice spaces to be implemented inexpensively and to be scaled quickly. Particularly with many teacher education programs moving to virtual options in response to COVID-19, digital practice spaces provide an alternative way for preservice teachers to gain experience with teaching scenarios in a safe manner.

As digital practice spaces emerge as a viable teacher education pedagogy, we pose the question: How do digital practice spaces align with preservice teachers' learning needs as they move between university coursework and field experiences? In other words, do digital practice spaces make appropriate approximations of practice by providing preservice teachers experiences that align with high quality clinical experiences?

To examine this problem, we focus our own experiences as instructors using digital practice spaces within teacher education coursework. We analyzed the core attributes of digital practice spaces through the framework for clinical practice set out in the American Association 
of Colleges for Teacher Education's (AACTE) 2018 report (2018a). We highlight hypothetical examples of how these attributes might be applied using the Discussion Leader practice spacea simulation of facilitating a PK-12 whole class discussion (Kaka et al., 2021; Marvez et al., 2021). Based on our analysis, we argue that digital practice spaces should be positioned as a method for improving the integration of clinical practice into teacher coursework by offering more opportunities for approximations of practice that complement clinical placements. This paper seeks to frame the roles that digital practice spaces can play in preparing preservice teachers to enter the complicated - and sometimes charged - situations they will face in classrooms.

\section{Framework}

Teaching is a complex practice requiring the integration of many different sources of knowledge, skills, and experiences. In framing this study, we drew on prior research on how people learn complex practices (Brown, Collins, \& Duguid, 1989; Hatano \& Inagaki, 1986; Lave \& Wenger, 1991; Resnick, 1987). A key component of learning complex skills is that the learning needs to be situated within an authentic setting where novices have the opportunity to learn from expert models, act, and revise based on their experiences (Lave \& Wenger, 1991). Given the highly technical and cognitive demands of modern teaching, it is useful to have opportunities for "bridging apprenticeships"- -simulated apprenticeship environments that connect the theory with practice (Resnick, 1987). Simulated environments provide opportunities for the intentional learning process of modeling, coaching, and fading (Brown, Collins, \& Duguid, 1989). Additionally, they allow novices to enact practice within multiple simplified, low-risk environments that prepare teachers for practice within authentic settings (Grossman et al., 2009). These experiences build the novice teachers adaptive expertise, the ability to respond 
flexibly to new situations, which requires a mix of both theoretical and experiential knowledge (Hatano \& Inagaki, 1986; Wetzel et al., 2015)

As such, the foundation of this study is that novice teachers need a carefully aligned, ordered, and scaffolded set of experiences in order to bridge theory in coursework with practice in an authentic clinical setting (Van Zoest \& Stockero, 2008). These should include early simulated enactments with digital tools, such as digital practice spaces, that increasingly move from less complex contexts into more complex and authentic contexts. In the next section, we describe the development of one such enactment, a digital practice space called Discussion Leader.

\section{An Illustrative Example of a Digital Practice Space: Discussion Leader}

Discussion Leader is a digital practice space on facilitating discussions of controversial issues in K-12 classrooms. In Discussion Leader, participants adopt the role of a teacher leading a class discussion on a controversial issue (e.g., immigration, gun violence, school monitoring of social media). Participants are given some background on the class including the readings the students were assigned prior to class and the demographics of the schools and are given a short introduction to their students. For the sake of approximation, the number of students is reduced to 3-5 students in order to make the simulation easier to navigate for novices.

Each practice space follows the same format. During the "Anticipate" stages, participants are asked what their goals are for the discussion based on the background materials they read. In the "Enact" stage, participants are shown various pieces of student dialogue and are asked how they would respond to that particular prompt (see Figure 1). The scenario dialogues were coauthored by software designers and researchers with detailed, iterative feedback from teacher educators, teachers, and high school students. Participants are given 2-3 response options for 
each scenario. Based on what response they select, a piece of student dialogue appears. The simulation is responsive; the narrative changes based on the decisions the participant makes. When participants make less-optimal instructional choices the student dialogue updates to reflect those choices.

The practice space concludes with a "Reflect" stage where they are asked about whether they achieved their goals within the simulation and what they might do differently in the future. Most participants complete the simulation in 20 minutes. By reflecting on their experience in simulations, participants work to build a greater understanding of the necessary components of practice needed to effectively facilitate a discussion about a controversial issue with students (Kaka et al., 2021). After concluding the practice space, participants debrief the exercise with an instructor. During the debrief, preservice teachers reflect with others on the decisions they made during the simulation and how they might handle these types of situations within a real classroom environment. 


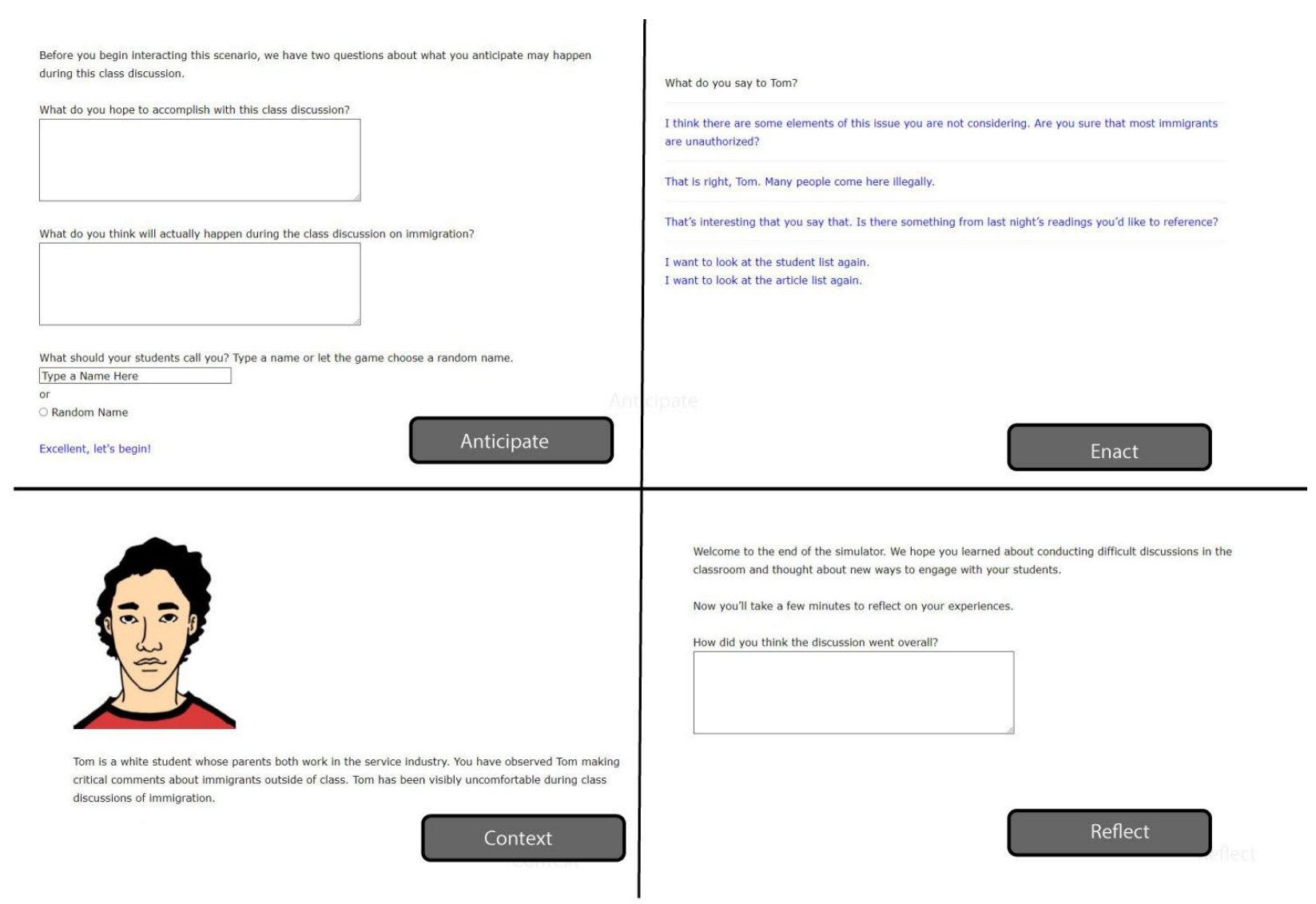

Figure 1. Screenshots from Discussion Leader: Immigration

\section{Relevant Literature}

\section{Approximating Whole-Class Discussions}

Facilitation of a classroom discussion is a complex practice requiring a suite of technical sub-skills including setting and enforcing norms, balancing classroom participation, teaching and rewarding the use of constructive dialogue strategies by students, and using effective questioning strategies (Beck, 2005; Hess, 2009; McAvoy \& Hess, 2013). Facilitating a whole-class discussion is one 'tool' in a novice teacher's toolbox when it comes to becoming a more effective educator (Ball \& Forzani, 2009; Grossman, Hammerness \& McDonald, 2009).

Integrating discussion into the secondary classroom has many positive effects. Murphy, Wilkinson, Soter, Hennessey, \& Alexander (2009) found that whole-class discussion supports 
critical thinking and student engagement. Hess \& McAvoy (2014) found that students who engaged in whole-class discussions around controversial issues were more likely to become civically engaged later in life. O'Connor (2002), discussion can positively impact students' depth of knowledge and ability to handle conceptual challenges in the classroom. Engle \& Conant (2002), found that class discussion can foster productive disciplinary engagement.

However, it is a challenging feat to lead a quality discussion since the ways in which teachers are prepared to lead discussions are varied (Baldinger \& Campbell, 2019; Bickmore \& Parker, 2014). This is especially true when the discussion is about an issue — such as racism, immigration, or gun control — that may make students and teachers alike uncomfortable (Pace, 2019). As a result, many teachers report feeling reticent about raising these issues in their classrooms, particularly in politically polarized environments (Rogers et al., 2017). Developing opportunities to practice leading these discussions within low-stakes environments can help preservice teachers develop the skills and confidence to address these issues within a live classroom environment (Kaka et al., 2021.

\section{Classroom Discussion, Approximations of Practice and the Role of Digital Practice Spaces}

Approximations of practice are a potentially useful tool in developing preservice teachers' capacity to enact complex teaching practices such as leading whole-class discussions on controversial topics. What differentiates approximations of practice from simulations generally is that approximations of practice explicitly abstracts out some of the complexity in order to focus the attention of novices on key details of practice (Grossman et al., 2009). This approach is grounded in research by Ericsson $(2002 ; 2014)$ on the value of focused repetition in moving beginners from novice to experienced within a specific domain of practice. Grossman et al., (2009) argue that it is preferable in designing approximations of complex practice to focus on a 
few key aspects of practice rather than attempting to holistically capture all of the messiness of the real-world situation. Subsequent research on approximations of practice have found that preservice teachers learn more within approximations of practice that are more tightly constrained and where they are focused on more granular aspects of practice (Campbell \& Elliott, 2015; Kavanagh et al., 2020).

By design, digital practice spaces are not fully immersive. Users access the scenarios using a basic web application and do not require the presence of human actors or specialized equipment used in other platforms. This has key benefits for cost and scalability; the costs and resources required for simulations is one reason why these approaches have not become more prevalent in teacher education coursework (Lindgren et al., 2016). However, there are other benefits that go beyond costs. Simplifying the environment allows the simulation to focus users' attention on key details (Aldrich, 2009; Gee \& Gee, 2017; Mislevy, 2013). This allows novices to focus on the key dimensions of practice, rather than being absorbed by extraneous details or overwhelmed by the complexity of the situation at hand. Further, research on simulations in education has found that often these experiences can produce feelings of cognitive dissonance (Dotger \& Ashby, 2010; Thompson et al, 2019), as they help educators observe that their own beliefs are not always aligned with their practice.

\section{Risk in Digital Practice Spaces}

Integrating the discussion of controversial issues has the potential to be risky for both students and teachers. Pace (2019) said that "the risks include emotional reactions that interfere with learning, inflammatory discourse threatening to students, and criticism from community members or school administrators" (p. 228). However, providing preservice teachers with the opportunity to practice leading a discussion in a low-stakes, online digital practice space, allows 
for many of these risks to be eliminated during learning. These include risks to both students and preservice teachers.

Many preservice teachers may be hesitant to broach controversial topics in their classrooms (Misco \& Patterson, 2007; Rogers et al., 2017). There are a variety of reasons that the literature cites for preservice teachers' hesitancy. One reason cited is that preservice teachers do not want to risk losing control of their classroom, whether due to a lack of management skills (Alvermann, et al., 1990; Barton \& Levstik, 2004; Day and Bryce, 2011) or pedagogical skills (Beck, 2013). Additionally, issues that are potentially controversial, such as terrorism, can create an emotionally charged atmosphere that not all preservice teachers are prepared to diffuse (Pace, 2019). Preservice teachers also fear administrator or parent push-back (Hess, 2009; Pace, 2019), and retribution if they unintentionally or intentionally disclose their political beliefs during these discussions (Journell, 2016; McAvoy \& Hess, 2013). However, practice spaces allow preservice teachers to partake in contained risk-taking, which Pace (2019) defines as, "a set of principled practices that encourages the teaching of controversial issues with sensitivity, pragmatism, integrity, and protection from harm" (p. 253).

When it comes to the fears preservice teachers have about taking risk and leading a discussion on a controversial issue, one major concern is that they will allow these fears to drive their instruction backwards, towards recitation and lower levels of Bloom's taxonomy (Parker, 2006), doing a huge disservice to their students. If they allow fear to drive their instruction, and they never implement whole-class discussion of these issues, no matter how uncomfortable, they force their students to miss out on a key aspect of democratic, higher-order thinking skill-based education (Chilcoat \& Ligon, 2001; Samuelsson, 2016). 
Students themselves are exposed to risks when untrained teachers engage their classes in discussions of controversial issues. One thing preservice teachers need to be concerned about is minimizing the risk of a student or group of students being marginalized in whole-class discussions (Wright et al., 2018). Preservice teachers need to be trained to facilitate more equitable power structures in their classrooms, such as through the practice of whole-class discussions. If they are not taught to do this, their students are at risk of being unintentionally marginalized while in the classroom (Calabrase Barton, et al., 2020; Wright, 2018). In wholeclass discussions, students also risk being judged by their peers and teachers (Dossin, 2002). This in part shifts with the age of the students, as older students are more mature and willing to put themselves "out there" in order to have a quality class discussion (Agee, 2000; Larson, 1997).

All of these risks are negated in the online practice space environment, though, since the preservice teachers are completing the simulation outside of a classroom, which allows them to be exposed to some of these practices before working with students.

\section{Objects of Inquiry}

The objects of inquiry used for this study were from AACTE's report, A Pivot Toward Clinical Practice, its Lexicon, and the Renewal of Educator Preparation (2018a). This report includes ten proclamations for highly effective clinical preparation. They include proclamations about pedagogy, skills, partnerships, infrastructure, development, empowerment, mutual benefits, common language, and expertise. Each proclamation has a subset of tenets that further detail each proclamation. The goal of these proclamations is to assist teacher preparation programs in becoming high-quality programs that create effective teachers through clinical practice and partnerships (AACTE, 2018a). Previous studies have used these proclamations to explore technology integration generally into clinically-centered teacher preparation programs 
(Sprague et al., 2020). In this study, we use these proclamations to specifically analyze the case of digital practice spaces.

\section{Modes of Inquiry}

To understand how digital practice spaces might fit into teacher preparation coursework and clinical practices, we examined our own practice using Discussion Leader. The authors are instructors at four different institutions, all of whom utilized Discussion Leader in their secondary methods courses to teach the high leverage practice of leading a group discussion on a controversial issue. Preservice teachers in each of the instructors' methods courses worked through two versions of Discussion Leader: "Discussion Leader: Immigration," which focused on immigration policies, and "Discussion Leader: Gun Violence," which focused on gun control policies. We used the AACTE proclamations as a framework to analyze and discuss how digital practice spaces currently and in the future inform a reimagining of clinical practice in teacher preparation, we utilized the proclamations as an analytic framework.

We each began with the executive summary (AACTE, 2018b). We asynchronously read and ranked the proclamations according to our perceptions of their existing or possible links to digital practice spaces for teacher preparation. As we did, we wrote memos (Groenewald, 2008) explaining our thought processes relevant to our subsequent decisions about which proclamations to include and in what fashion. Next, we conducted a researchers' meeting to discuss similarities and differences in our rankings (Miles et al., 2019). Finally, we focused on the full report (AACTE, 2018a), paying particular attention to each tenet of the ten proclamations, which we used as an exercise in data triangulation (Maxwell, 2013; Ravitch \& Carl, 2016).

\section{Substantiated Conclusions}


Based on our analysis of the AACTE proclamations, we identified two categories of proclamations, those that were immediately relevant to digital practice spaces and those which might be relevant if digital practices spaces expand in size and scope. The four proclamations that directly and immediately align with the theoretical, conceptual, and practical underpinnings of digital practice spaces are: the Central Proclamation, the Pedagogy Proclamation, the Skills Proclamation, and the Common Language Proclamation. We begin our analysis with a description of the specific proclamation. We then describe how digital practice spaces can support the aspect of clinical practice highlighted in the proclamation and provide examples based on our experiences implementing the Discussion Leader digital practice space in our methods courses. From there, we proceed to examine the remaining six proclamations. These represent the horizons of digital practice spaces within teacher preparation, a task we undertake as a set of informed provocations, or envisioning how simulations could be made and designed to support the proclamations not currently supported. Finally, we discuss the future possibilities of the ways in which simulations could connect to the proclamations to strengthen clinical partnerships and practice.

\section{Proclamations Directly and Immediately Aligned}

\section{The Central Proclamation}

We begin with the Central Proclamation, which posits that "clinical practice is central to high-quality teacher preparation" (AACTE, 2018a, pg. 13). This proclamation has five main tenets that we discussed and with which we overwhelmingly agree. Course work and field experiences are intrinsically linked and should be explicitly aligned to support one another. This is the basis of high-quality teacher preparation. Preservice teachers need to experience a variety of diverse placements, and be observed in them through authentic assessments of practice. These 
experiences should be embedded throughout their program, rather than at the end in one culminating student teaching experience.

Digital practice spaces support this proclamation by increasing the amounts and types of approximations of practice that could be integrated within preservice teachers' coursework prior to clinical placement. A significant barrier to clinical placements is the lack of coherence between university coursework and field placements (Bain \& Moje, 2012; Francis, 2017). As a result of this, preservice teachers may not be able to immediately connect what they are learning in their coursework to what they are doing in their clinical placement. Additionally, having preservice teachers practice complex skills, such as leading a discussion on a controversial issue, without first practicing these skills, opens up potential avenues for harm to students.

Digital practice supplements and builds on their pedagogical knowledge by allowing preservice teachers in their coursework a low-risk practice of the research-based skills needed to be an effective teacher before they attempt the lessons in their field experiences. When we implemented Discussion Leader in preservice teacher education courses, we assigned one of the digital practice spaces to be completed prior to class. We provided formative feedback based on their initial simulation responses and further instruction on the nature of leading a whole class discussion. The preservice teacher then had the opportunity to incorporate this feedback right away in a digital practice space assigned immediately after class. Then, in conjunction with instruction on research-based best practices for leading a discussion, the preservice teachers took what they learned in class and applied it in their field experiences.

\section{The Pedagogy Proclamation}

The Pedagogy Proclamation maintains that "as pedagogy is the science of teaching, the intentional integration of pedagogical training into an educator preparation program is the 
cornerstone of effective clinical practice" (AACTE, 2018a, pg. 15). There are two tenets of this proclamation, that pedagogical training is the heart of educator preparation, and that it guides effective clinical practice. We take this proclamation as a core premise of effective clinical educator preparation. Training in the complex frames and choices of available pedagogies enables preservice teachers to approach possible situations and navigate the choices they must make in front of students.

How might digital practice spaces fit within an approach to clinical preparation that centers pedagogical training? Digital practice spaces provided the opportunity for our preservice teachers to break down a novel situation, consider multiple pathways forward, and reason through the consequences of their choices. In our own courses, we observed that Discussion Leader practice space offered our preservice teachers the space to practice for a specific, difficult situation by offering the premise of a controversial discussion with students holding multiple viewpoints, drawing upon sources in a variety of ways, and playing off of each other's comments. We found that the simulation broke down the many pedagogical moves an experienced teacher typically makes which are sensitive to many factors. Slowing down and considering these factors functioned as a type of apprenticeship for preservice teachers. Through discussing the options they have available, we found that the preservice teachers were more attentive to various decisions and how they might affect real-life students.

\section{The Skills Proclamation}

The Skills Proclamation believes that "clinical practice includes, supports, and complements the innovative and requisite skills, strategies, and tools that improve teacher preparation by using high-leverage practices as part of a commitment to continuous renewal for all learning sites" (AACTE, 2018a, pg. 17). The two tenets of this proclamation - that we can 
think innovatively about educator preparation and that the ways we prepare teachers are aligned, research-based, and professionally embedded - assert the importance of contextual preparation. Using the strengths of PK-12 mentoring spaces and the higher education perspective, mentors and stakeholders span boundaries to mentor the skill-building of preservice teachers.

Digital practice spaces can support skill-building in two specific one ways. One, they focus the attention of the preservice teachers on specific aspects of practice. For example, in Discussion Leader the simulation is designed to focus the attention of the preservice teacher users on the emotional responses of the student avatars in the simulation. When practice space users avoid engaging with hurtful comments, for example, the student avatars become noticeably more emotionally distraught and withdrawn. This design focuses on the fundamental need to pay close attention to students and respond promptly when students violate discussion norms. When we used Discussion Leader in our classes, we found that our preservice teachers were able to identify when the conversation started to escalate. Preservice teachers were curious about what might happen in a real classroom with similar topics. As a result, the Discussion Leader simulation focused their attention on how different types of students experienced the discussion.

Second, digital practice spaces allow opportunities for formative feedback. Instructors can use digital practice spaces to identify specific areas where preservice teachers may need additional support. In some of our classes, preservice teachers mentioned that they might not intervene in the discussion if students use offensive language in order to "stir the pot." A teacher educator might use this as an opportunity to point out ways that this approach could be detrimental to certain students, particularly those from marginalized communities. As a result, the digital practices spaces provide opportunities for discrete research-based skills building through targeted formative feedback. 


\section{The Common Language Proclamation}

The final proclamation that we agreed upon is the Common Language Proclamation, which states, "coalescing the language of teacher preparation and teaching around a common lexicon facilitates a shared understanding of and reference to the roles, responsibilities, and experiences essential to high-quality clinical preparation" (AACTE, 2018a, pg. 38). This proclamation has three tenets that address implementing a common lexicon, applying it to understand roles and responsibilities, and using it to shape broader conversations. We agreed that using common terms enables stakeholders to better understand and navigate the complexities of practice.

Digital practices promote a shared understanding by giving a common lexicon for preservice teachers to discuss issues of practice prior to clinical placements. Teacher educators can use the digital practice spaces as a shared experience that they can refer back to as they describe research-based practices. For example, in Discussion Leader, one of the issues that users must contend with is that one of the student avatars, a white male, dominates the conversations and interrupts other students. An approach that some of us took was to encourage our preservice teachers to reflect on how to ensure equitable opportunities to engage all students in the discussion. Since all preservice teachers had this shared experience, even within the simulation, it offered them a shared language to discuss how they approached the situation to coconstruct knowledge about the strategies they might employ within a real-life classroom setting. By introducing shared experiences of practice within the classroom, digital practices spaces may create a common lexicon within the classroom. Having a common lexicon helped our preservice teachers make broader links to wider discourse on teaching within the profession.

\section{Informed Provocations and Future Possibilities}


Our next undertaking is to (re)envision how digital simulations could be designed to support other, less immediately related, aspects of clinical placements. We do so as informed provocations. By informed provocations, we mean to describe the present work as seeking to provoke a substantive expansion of existing approaches to teacher preparation as described in the AACTE proclamations--namely, the leveraging of digital simulations in that endeavor.=. These remaining six proclamations focus on the critical nature of effective, reciprocal, and mutually beneficial partnerships between Educator Preparation Programs and PK-12 institutions. They discuss the notion that these partnerships must continue to develop and that educators' expertise is invaluable in the development of teacher education. While Discussion Leader does not currently support these proclamations, we do see possibilities in the future for connecting with district partners and preservice teachers to more intentionally design practice spaces based on clinical partnerships.

The Partnership Proclamation is built on the belief that clinical partnerships are the foundation of highly effective clinical practice (AACTE, 2018a). The Infrastructure Proclamation says that "sustainable and shared infrastructure is required for successful clinical partnership" (AACTE, 2018a, p. 24), while the Mutual Beneficial Proclamation holds firm to the belief that school- and university-based teacher educators need to work together to educate future teachers, because both "play necessary, vital, and synergistic roles in clinical educator preparation" (AACTE, 2018a, p. 33). We envision a system where digital practice spaces can strengthen the partnerships between EPPs and PK-12 institutions and help preservice teachers grow in their specific needs. This can be accomplished through such steps as teacher educators and mentors co-designing practice space scenarios, clear systems of feedback for both mentors 
and preservice teachers on their experiences with the tools, and creating digital practice spaces that can be experienced by mentors and student teachers together becoming objects of inquiry.

Finally, the Developmental Proclamation, the Empowerment Proclamation, and the Expertise Proclamation all support the need for specialized knowledge of the development and growth of new teachers through supportive partnerships and provided opportunities for growth. Digital practice spaces can support this growth through providing opportunities for preservice teachers to develop and implement their own scenarios and identify what types of the feedback they might give other preservice teachers. Ultimately, this will allow preservice teachers to be empowered in directing their learning and tailoring experiences to their needs.

\section{Conclusion}

Our analysis found that affordances of digital practice spaces were aligned with many of the $A A C T E$ proclamations for clinical practice. This analysis suggests that digital practice spaces may be a promising tool for incorporating clinical practice into coursework prior to preservice teachers being in the classroom as they offer more opportunities for approximations of practice that complement clinical placements. More broadly, our work contributes to the movement of practice-based teacher education (Ball \& Forzani, 2009; Grossman et al., 2009) by creating new modalities for practice and reflection within an intentional trajectory of learning. Discussion Leader and other digital practice spaces can create rich opportunities for pre-clinical work, or work that teacher educators can do to improve preservice teachers' foundational skills before entry into the classroom. These tools also bridge the gap between methods courses and clinical field experiences, and they can be used to support preservice teachers once they are in the field full time as well. 
This work is also significant and timely because of the way the COVID pandemic of 2020 shocked teacher education programs throughout the country, blindsided by the closure of schools and universities, leaving many scrambling to piece together meaningful clinical experiences for preservice teachers (Quezeda et al., 2020). Now that we have a better understanding of how a pandemic can affect institutions, and specifically teacher preparation, it is imperative that teacher education programs become more versatile and elastic in enacting their courses and experiences. Discussion Leader, and other digital practice spaces, offer the kinds of tools teacher educators can use to replicate the authentic experiences of live teaching for preservice teachers learning independent of their ability to be in schools. 


\section{References}

Agee, J. (2000). What is Effective Literature Instruction? a Study of Experienced High School English Teachers in Differing Grade- and Ability-Level Classes. Journal of Literacy Research, 32(3), 303-348. https://doi.org/10.1080/10862960009548084

Aldrich, C. (2009). Virtual worlds, simulations, and games for education: A unifying view. Innovate: Journal of Online Education, 5(5).

Alvermann, D. E., O'Brien, D. G., \& Dillon, D. R. (1990). What teachers do when they say they're having discussions of content area reading assignments: A qualitative analysis. Reading Research Quarterly, 25, 296-32

American Association of Colleges for Teacher Education (AACTE) (2018a). A pivot toward clinical practice, its lexicon, and the renewal of educator preparation. Washington, DC. Retrieved from: https://aacte.org/professional-development-and-events/clinical- practicecommission-press-conference

American Association of Colleges for Teacher Education (AACTE) (2018b). A pivot toward clinical practice, its lexicon, and the renewal of educator preparation: Summary brief. Washington, DC. Retrieved from: https://aacte.org/professional-development-andevents/clinical- practice- commission-press-conference

Baldinger, E. E., \& Campbell, M. P. (2019). Cases of learning to respond to errors through approximations of leading whole-class discussions. In 41st Annual Meeting of PME-NA (pp. 1066-1075).

Ball, D. L., \& Forzani, F. M. (2009). The work of teaching and the challenge for teacher education. Journal of Teacher Education, 60(5), 497-511. doi:10.1177/0022487109348479 
Bain, R. B., \& Moje, E. B. (2012). Mapping the teacher education terrain for novices. Phi Delta Kappan, 93(5), 62-65. doi:10.1177/003172171209300514

Barton, K. C., \& Levstik, L. S. (2004). Teaching history for the common good. Mahwah, NJ: Erlbaum.

Bautista, N. U., and Boone, W. J. (2015). "Exploring the impact of TeachME lab virtual classroom teaching simulation on early childhood education majors' self-efficacy beliefs." Journal of Science Teacher Education 26: 237-262. doi:10.1007/s10972-0149418-8.

Beck, T. A. (2005). Tools of deliberation: Exploring the complexity of learning to lead elementary civics discussions. Theory \& Research in Social Education, 33(1), 103-119.

Beck, T.A. (2013) Identity, discourse, and safety in a high school discussion of same-sex marriage, Theory \& Research in Social Education, 41:1, 1-32, doi:10.1080/00933104.2013.757759

Bickmore, K., Parker, C. (2014). Constructive conflict talk in classrooms: Divergent approaches to addressing divergent perspectives. Theory \& Research in Social Education, 42, 291335.

Brown, J. S., Collins, A., \& Duguid, P. (1989). Situated cognition and the culture of learning. Educational Researcher, 18(1), 32-42.

Calabrese Barton, A., Tan, E., Birmingham, D. J. (2020). Rethinking high-leverage practices in justice-oriented ways. Journal of Teacher Education, 71(4), 477-494.

Campbell, M. P., \& Elliott, R. (2015). Designing approximations of practice and conceptualising responsive and practice-focused secondary mathematics teacher education. Mathematics Teacher Education and Development, 17(2), 146-164. 
Chilcoat, G. W. \& Ligon, J. A. (2001). Discussion as a means for transformative change: Social studies lessons from the Mississippi Freedom Schools. The Social Studies(September/October), 213-219.

Clark, C., \& Lampert, M. (1986). The study of teacher thinking: Implications for teacher education. Journal of Teacher Education, 37(27). 27-31.

Day, S. P., \& Bryce, T. G. (2011). Does the discussion of socio-scientific issues require a paradigm shift in science teachers' thinking?. International Journal of Science Education, 33(12), 1675-1702. Doi:https://doi.org/10.1080/09500693.2010.519804

Darling-Hammond, L . (2014). Strengthening clinical preparation: The holy grail of teacher education. Peabody Journal of Education, 89(4): 547-561.

DeGraff, T. K., Schmidt, C. M., Waddell, J. H. (2015) Field-based teacher education in literacy: Preparing teachers in real classroom contexts. Teaching Education 26: 366-382.

Dennis, D., Burns, R. W., Tricarico, K., Van Ingen, S., Jacobs, J., \& Davis, J. (2017). Problematizing clinical education: What is our future? In R. Flessner \& D. Lecklider's (Eds.), The power of clinical preparation in teacher education (pp. 1-20). New York, NY: Rowman \& Littlefield.

Dotger, B. H., \& Ashby, C. (2010). Exposing conditional inclusive ideologies through simulated interactions. Teacher Education and Special Education: The Journal of the Teacher Education Division of the Council for Exceptional Children, 33(2), 114-130. https://doi.org/10.1177/0888406409357541.

Dossin, M. M. (2002.) Why won't they talk? College Teaching, 50(1), 3. 
Engle, R. A., \& Conant, F. R. (2002). Guiding principles for fostering productive disciplinary engagement: Explaining an emergent argument in a community of learners classroom. Cognition and Instruction, 20, 399-483.

Ericsson, K. A. (2002). Attaining excellence through deliberate practice: Insights from the study of expert performance. In M. Ferrari (Ed.), The pursuit of excellence in education (pp. 21-55). Hillsdale, NJ: Erlbaum.

Ericsson, K. A. (2014). Why expert performance is special and cannot be extrapolated from studies of performance in the general population: A response to criticisms. Intelligence, $45,81-103$.

Francis, A.T. (2017). Reforming only half: A study of practice-based teacher education in traditional field placements. Mid-Western Educational Researcher, 29(3), 235-260.

Gee, E. \& Gee, J.P. (2017) Games as distributed teaching and learning systems. Teachers College Record 119 (12) (pp. 1-22). Retrieved from https://www.tcrecord.org/content.asp? contentid=22062

Groenewald T. (2008). Memos and memoing. In: Given L, ed. The SAGE Encyclopedia of Qualitative Research Methods. Thousand Oaks, CA: Sage; 2008:506-507.

Grossman, P. L., Compton, C., Igra, D., Ronfeldt, M., Shahan, E., \& Williamson, P. (2009). Teaching practice: A cross- professional perspective. Teachers College Record, 111(9), $2055-2100$.

Grossman, P. L., Hammerness, K., \& McDonald, M. (2009). Redefining teaching, re-imaging teacher education. Teachers and Teaching: Theory and Practice, 15(2), 273-289. doi:10.1080/13540600902875340 
Hatano, G. \& Inagaki, K. (1986). Two courses of expertise. In H. Stevenson, H. Azuma, \& K. Hakuta (Eds.), Child development and education in Japan (pp. 262-272). New York, NY: Freeman.

Hess, D. E. (2009). Controversy in the classroom: The democratic power of discussion. New York: Routledge.

Hess, D. E., \& McAvoy, P. (2014). The political classroom: Evidence and ethics in democratic education (1st ed.). Routledge. https://doi.org/10.4324/97813157388

Howell, H., \& Mikeska, J. N. (2021). Approximations of practice as a framework for understanding authenticity in simulations of teaching authenticity in simulations of teaching. Journal of Research on Technology in Education, 53(1), 8-

20. https://doi.org/10.1080/15391523.2020.1809033

John, P. D. (2007). Lesson planning and the student teacher: Rethinking the dominant model. Journal of Curriculum Studies, 38(4), 483-498.

Journell, W. (2016). Making a case for teacher political disclosure. Journal of curriculum theorizing, 31(1).

Kaka, S.J., Littenberg-Tobias, J., Kessner, T., Francis, A.T., Kennett, K., Marvez, G. \& Reich, J. (2021). Digital simulations as approximations of practice: Preparing preservice teachers to facilitate whole-class discussions of controversial issues. Journal of Technology and Teacher Education, 29(1), 67-90.

Kavanagh, S. S., \& Danielson, K. A. (2020). Practicing justice, justifying practice: Toward critical practice teacher education. American Educational Research Journal. https://doi.org/10.3102/0002831219848691. 
Kavanagh, S. S., Metz, M., Hauser, M., Fogo, B., Taylor, M. W., \& Carlson, J. (2020).

Practicing Responsiveness: Using Approximations of Teaching to Develop Teachers' Responsiveness to Students' Ideas. Journal of Teacher Education, 71(1), 94-107. https://doi.org/10.1177/0022487119841884

Larson, B.E. (1997) Social studies teachers' conceptions of discussion: A grounded theory study, Theory \& Research in Social Education, 25:2, 113-136, doi:

$10.1080 / 00933104.1997 .10505798$

Lampert, M., Franke, M., Kazemi, E., Ghousseini, H., Turrou, A., Beasley, H., Crowe, K. (2013). Keeping it complex: Using rehearsals to support novice teacher learning of ambitious teaching. Journal of Teacher Education, 64(3), 226-243.

Lave, J. \& Wenger, E. (1991). Situated Learning: Legitimate Peripheral Participation. Cambridge University Press.

Lindgren, R., Tscholl, M., Wang, S., Johnson, E. (2016). Enhancing learning and engagement through embodied interaction within a mixed reality simulation. Computers \& Education, $95,174-187$.

Marvez, G. R., Kessner, T. M., Littenberg-Tobias, J., \& Reich, J. (2021, July). Virtual Branching Practice Spaces to Prepare Educators for Political Discourse in the Classroom. Tech Demo presented at the Connected Learning Summit (Virtual)

Maxwell, J. A., 2013. Qualitative Research Design: An Interactive Approach. (3rd ed.). Sage Publications.

McAvoy, P., \& Hess, D. (2013). Classroom deliberation in an era of political polarization. Curriculum Inquiry, 43(1), 14-47. 
Miles, M. B., Huberman, A. M., \& Saldaña, J. (2019). Qualitative data analysis: Amethods sourcebook (4th ed.). Sage.

Misco, T., \& Patterson, N. C. (2007). A study of pre-service teachers' conceptualizations of academic freedoms and controversial issues. Theory and Research in Social Education, $35,520-550$.

Mislevy, R. J. (2013). Evidence-centered design for simulation-based assessment. Military Medicine, 178(10S), 101-114.

Murphy, P.K., Wilkinson, I.A., Soter, A.O., Hennessey, M.N., \& Alexander, J.F. (2009). Examining the effects of classroom discussion on students' comprehension of text: A meta-analysis. Journal of Educational Psychology, 101(3), 740- 764. doi:10.1037/a0015576

O'Connor, M. C. (2002). “Can any fraction be turned into a decimal?” A case study of a mathematical group discussion. In Learning Discourse (pp. 143-185). Springer, Dordrecht.

Pace, J. L. (2019) Contained risk-taking: Preparing preservice teachers to teach controversial issues in three countries. Theory \& Research in Social Education, 47(2), 228-260, doi: $\underline{10.1080 / 00933104.2019 .1595240}$

Parker, W. C. (2006). Talk isn't cheap: Practicing deliberation in school. Social Studies and the Young Learner, 19(1), 12-15.

Philip, T. M., Souto-Manning, M., Anderson, L., Horn, I., J. Carter Andrews, D., Stillman, J., \& Varghese, M. (2019). Making justice peripheral by constructing practice as "core": How the increasing prominence of core practices challenges teacher education. Journal of Teacher Education, 70(3), 251-264. 
Quezada, R. L., Talbot, C. \& Quezada-Parker, K. B. (2020). From bricks and mortar to remote teaching: a teacher education programmes's response to Covid 19. Journal of Education for Teaching. https://doi.org/10.1080/02607476.2020.1801330

Ravitch, S. M., \& Carl, N.M. (2016). Validity: Process, strategies, and considerations. In S.M. Ravitch \& N. M. Carl (Eds.), Qualitative research: Bridging the conceptual, theoretical, and methodological (pp. 185-214). Sage.

Reich, J., Kim, Y. J., Robinson, K., Roy, D., \& Thompson, M. (2018, July). Teacher practice spaces: examples and design considerations [Paper presentation]. 13th International Conference of the Learning Sciences, Inc., London, United Kingdom. https://research.utwente.nl/files/102267789/ICLS2018_Volume 1_Final.pdf\#page=688

Rogers, J., Franke, M., Yun, J.-E. E., Ishimoto, M., Diera, C., Geller, R. C., Berryman, A., \& Brenes, T. (2017, October). Teaching and learning in the age of Trump: Increasing stress and hostility in America’s high schools. UCLA Institute for Ideas, Democracy, Education, and Access. https://idea.gseis.ucla.edu/publications/teaching-and-learning-inage-of-trump

Resnick, L. B. (1987). The 1987 presidential address learning in school and out. Educational Researcher, 16(9), 13-54.

Samuelsson, M. (2016). Education for deliberative democracy: A typology of classroom discussions, Democracy and Education, 24(1).

Self, E. A. \& Stengel, B. S. (2020). Toward anti-oppressive teaching: Designing and using simulated encounters. Harvard Education Press.

Sprague, D.R., Parsons, S.A., \& Parker, A.K. (2020). Technology infusion in clinical experiences. In A.C. Borthwick, T.S. Foulger, \& K.J. Graziano (Eds.), Championing 
technology infusion in teacher preparation: A framework for supporting future educators (131-148). Portland, OR: International Society for Technology in Education.

Thompson, M., Owho-Ovuakporie, K, Robinson, K., Kim, Y. J., Slama, R \& Reich, J. (2019) Teacher moments: A digital simulation for preservice teachers to approximate parentteacher conversations, Journal of Digital Learning in Teacher Education, 35(3), 144-164. https://doi.10.1080/21532974.2019.1587727

Van Zoest, L. R., \& Stockero, S. L. (2008). Synergistic scaffolds as a means to support preservice teacher learning. Teaching and Teacher Education, 24(8), 2038-2048.

Wetzel, A. P., De Arment, S. T., \& Reed, E. (2015). Building teacher candidates' adaptive expertise: engaging experienced teachers in prompting reflection. Reflective Practice, $16(4), 546-558$.

Wright, C., Wendell, K. B., \& Paugh, P. P. (2018). "Just put it together to make no commotion:" Re-imagining urban elementary students' participation in engineering design practices. International Journal of Education in Mathematics, Science and Technology, 6(3), 285301. doi: 10.18404/ijemst.428192

Yendol-Hoppey, D., \& Hoppey, D. (2018). Outcomes of high-quality clinical practice in teacher education. Charlotte, NC: Information Age Publishing. 